\title{
ABUSALT DE DENIA
}

\author{
Por \\ ANGEL GONZÁLEZ PALENCIA
}

Este texto, que reeditamos porque aún tiene actualidad cientifica, se refiere a uno de los personajes intelectuales más notables de las letras árabes en Sharq Al-Andalus, Abu Salt de Denia, y ha sido escrito, en el marco de su tesis doctoral, por uno de los más eminentes arabistas españoles del siglo XX. Ángel González Palencia.

En efecto, González Palencia (nacido en Horcajo de Santiago, Cuenca, 1889, y fallecido en accidente de coche, cerca de su pueblo natal, en 1949) compartió con sus maestros arabistas el valenciano Julián Ribera y el aragonés Miguel Asín Palacios el rigor científico, la amplitud de miras y temas y una asombrosa capacidad de trabajo y de publicaciones. Estas últimas abarcan amplios campos de historia y edición de textos de literatura española, de historia de América, de catalogación de archivos y de historia local, especialmente conquense. Como arabista, se le debe cuatro gruesos volúmenes sobre los mozárabes toledanos, la edición con Codera de la Tákmila de lbn Al-Abbār de Valencia, la edición y traducción del catálogo de las ciencias de Al-Farabi, la traducción de la obra maestra de Ibn Tufail "El filósofo autodidacta", etcétera. Su capacidad de amplias y cuidadosas sintesis le permitió hacer dos manuales, que tuvieron muchas ediciones, sobre "Historia de la España musulmana" e "Historia de la literatura arábigo-españolan y un precioso capítulo del volumen inglés de "El Legado del Islam", que resumió en su discurso de recepción en la Academia de la Historia sobre "El Islam y Occidente". Miembro del Cuerpo de Archiveros y Bibliotecarios. Académicos de la Historia (1930) y de la Lengua (1940), fue heredero directo de Ribera, al que sucedió en la cátedra de Literatura Árabe en la Universidad de Madrid (1927), y de Asín, al que también sucedió en la dirección de la Escuela de Estudios Arabes y la revista "Al-Andalus" (1944). Su fallecimiento accidental (1949), cuando apenas contaba con 60 años de edad, fue un golpe nefasto para los estudios árabes en Madrid: Uno se puede imaginar lo que hubieran sido esos estudios si el maestro húbiera vivido veinte años más, con su capacidad de trabajo, personal y colectivo, y su espléndida salud. 
De su tesis doctoral, publicada en Madrid por el Centro de Estudios Históricos de la Junta para ampliación de estudios e investigaciones científicas en 1915, bajo el título Rectificación de la mente. Tratado de lógica por Abusalt de Denia. Texto árabe, traducción y estudio previo, publicamos el capítulo sobre la biobibliografía de este sabio deniense, cuyo carácter multidisciplinar ha sido recientemente puesto en relieve por $M$. J. Rubiera Mata, "Literatos del Sharq Al-Andalus: Abu-s-salt de Denia e lbn Dihya de Calpes, Revista del Institu to de Estudios Alicantinos, Alicante, núm. 36, 1982, pp. 33-43.

\section{VIDA Y OBRAB DE ABUBALT}

Abusalt Omeya ben Abdelaziz ben Abisalt nació en Denia el año 460 de la hégira (1067-1068 de Jesucristo) (1).

Ninguna noticia nos han dejudo sus biografos acerca de su familia; y respecto a su educación, solamente Abenjalicán indica que estudió con varios maestros de la comarca de Denia, entre ellos con el cadi Abulgualid Alguacaxí. Era éste, según Abenpascual (2), el hombre de erudición más univursal en au tiempo, uno de los más sabios gramáticos, entendido en lexicologia, en el sentido de los versos, arte métrica y elocuencia; a la cualidad de prosista elegante reunia la de buen versiflcador, docto en tradiciones $\mathrm{y}$ hochos históricos, muy

(1) A benjalicán, I, 228. Almacari (Analectes, I, 580), copiando a Abonsaid, lo llama ol Sevillano; pero, aparto do que este denominativo no indica siempre el pueblo de pro. cedencia, sino a veces ol de residencia únicamente, es go neral on los deráás biógrafos la iudicación de quéfué na. tural de Denia. Cfr. Benabioseibia, II, 52.

(2) Assila (ed. Codera), biog 1323. 
versado en los fundamentos dogmáticos y jurj́dicos, conocedor de muchas sentencias legales, da. das por jurisconsultos de varios países; práctico en materia de contratos y sucesiones hereditarias, seguro en la ciencia del cálculo y la geometria, y de tạn sólida instrucción, tan erudito, que estilba al tanto de los sistemas y opiniones de los filósofos, en cuyo examen critico mostraba sagacidad, tino y penetración no comunes, de tal modo que de él podía decirse aquello del poeta:

Las ciencias hasta tal punto dominaba que todo saber en su mente reunía (1).

Cumo se verá después, este carácter enciclopédico do la cultura del maestro se reflejó también en el discipulo, que brilla en todos los ramos del saber humano, exceptuando las ciencias religiosas; parece como si el trato con la filosofia y con las ciencias profanas, hubieran acentuado en él el racionalismo que sin duda su maestro le inculcara.

No sabemos si estudió solarnente en Denia, o si estudió también en otras partes, siguiendo la costumbre de aquella época; quizá residiera algún tiempo en Sevilla, y a ello deba la denominación de sexillano que le da Abensaid (2). Unicamente nos consta que por las fiestas de los sacrificios

(1) Cfr, los artículos de D. Julián Ribera en El Archivo (Revista de Denia, 1857), titulados La elegia árabe de Valencia y su autor, to mo I, págs. 380, 388 y 398. Idem, Menéndez Pidal, R., La elegía árabe de Valencia, apud. Home. naje a D. F. Cudera, 393.

(2) Cfr. Aimogrib, ms. árabe do la R. Academia de la Historia, núm. 80 , fol. 119-12u v..$^{\circ}$ Por el interés que tiene estu fuente inédita utilizada por Almacari, doy ol tex. 
(10 de Dulhicha) del año 489/1095 llegó a Alejan. dria, acompañado de su madre. Es lo más probable que en Alejandría se dedicara Abusalt al estadio con gran entusiasmo. Consta también que es. tuvo en el Cairo durante algún tiempo.

Reinaba a la sazón en Egipto el califa fatimí Almustali Abulcasim Ahmed, hijo de Almostansir Abutemin Maád; pero el que llevaba las riendas. del gobierno era Xahanxah, hijo del Emir Alchiux (Mirguch), Béder Alchamali, general armenio traído por Almostánsir, para sujetar a los negros

to de la biografía, omitiondo los fragmentos de poesía que intercala.

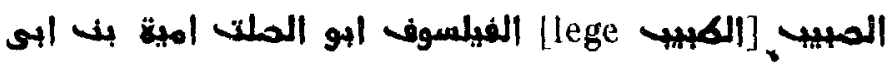

الصلت اللشبلى

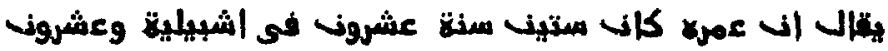

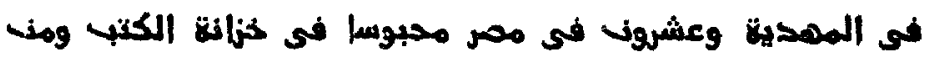

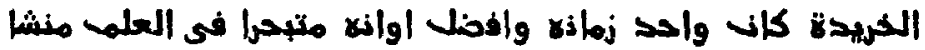

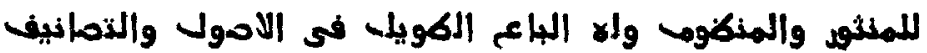

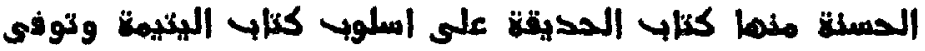

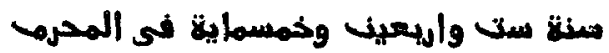

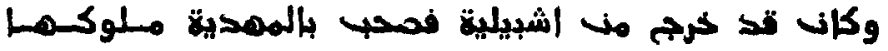

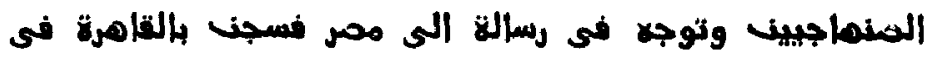

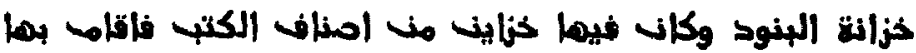

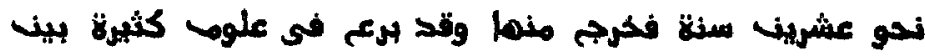

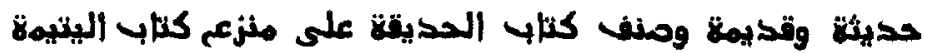

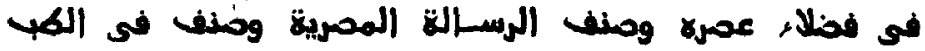

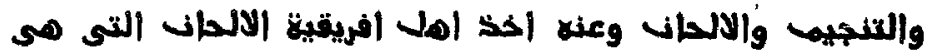

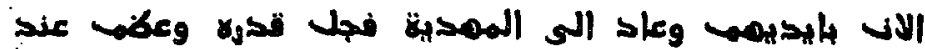

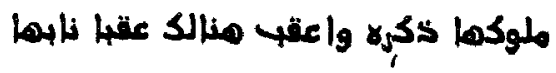


de la guardia real y para combatir a los turcos Confirmado Xahanxah por Almustali en el titulo de Málic Aláfdal, sólo pensó en recuperar lns provincias perdidas por las conquistas de los seljucies, mientras que los ismaelíes, separados de los fatimíes, fundaban en Persia y en el norte de Siria los célebres estados de los Asesinos (Hachachin), y los Cruzados aparecian en el horizonte. Málic Aláfdal tomó Jerusalem a los ortoquíes, gobernadores de los seljucies, en 1098, y al año siguiente entraba Godofredo de Bouillon por asalto en la Ciudad Santa. A Almustáli sucedió en 495/1101 Alamir $\Lambda$ buali Mansur, de cinco ahos de edad; pero Aláfdal era el que seguia gobernando, hasta que el caLifa, envidioso de su poder, le hizo asesinar el $512 /$ 1121, suceso que acentuó la rápida decadencia de la dinastia fatimí (1).

En este escenario de iuchas interiores y exteriores, poco propicio en verdad para los reposados trabajos del espíritu, es donde, sin embargo, se deslizir la épocia de más intensa vida científica de nuestro filósofo. Una aventura casi novelesca, aunque perfectamente histórica, fué quizá el motivo principal que puso de relieve sus talentos en la corte del califa fatimí, en el año 505/1111. He aquí cómo nos la refiere Benabioseibia (2):

*Un barco cargado de cobre, que navegaba con rumbo a Alejandría, naufragó muy cerca de ella.

(1) Cfr. Huart: Histoires des arabes (París, Gouthner, 1912) $1,348$.

(2) A él se la contó on el Cairo el año 6:32/12.34 el jeque Sedid Ad lin el Mantiquí. Benabioseibia, loc. cit. 
A nadie se le ocurría un medio para sacarlo a flote, cuando Abusalt pensó en el asunto y creyó haber dado con la solución. Reunió a los nobles del Amir Alchiux, rey de Alejandria, y les expuso que él se comprometía a sacar a flote el barco naufragado, con todo lo que contenia, siempre que le $\mathrm{fa}$. cilitasen todos los medios que necesitaba. Los nobles se admiraron del ingenio de Abusalt, se alégraron mucho y le rogaron que pusiera en práctica lo que habia pensado, para lo cual se le dieron todos los instrumentos que pidió, gastándose en ello una gran cantidad de dinero. Una vez que lodo lo tuvo preparado, lo colocó en un barco grande que hizo situar paralelo al barco naufragado. Echó como amarras cables trenzados de seda y mandó que descendiesen hombres prácticos y las amarrasen al barco naufragado. Abusalt habia construido ciertos aparatos, fundándose en reglas geométricas, para extraer del agua los cuerpos pesados que hubiera en el barco, y dió a todos los obreros las ordenes oportunas para que conocieran su manejo.

Los obreros empezaron a trabajar, y los cables iban subiendo hacia ellos, poco a poco, enrollándose en los tornos que manejaban, hasta que apareció el barco naufragado y llegó casi a la superficio del agua; pero en este momento se rompieron los cables, y volvió a sumergirse en el fondo del mar.

Abusalt habia hecho con gran ingenio sid aparato para sacar a flote el barco, pero el destino no le ayudó. El rey se irritó por los muchos gastos que hacía ocasionado la construcción de aquel apa. rato, y mandó aprisionar a Abusalt (aun cuando éste no lo merecia), permaneciendo en la prisión 
algún tiempo, hasta que los nobles intercedieron por él ante el rey que lo miındó soltar.»

Sin duda la prisión no pasó de un arresto, pues Abensald dice que cué detenido en la sala de banderas, donde estaba también la biblioteca», en la cual cuenta que se dedicó al estudio durante veinte anos, saliendo hecho un sabio en toda clase de ciencias (1). Esta última afirmación, como igualmente la división de la vida de Abusalt, en tres periodos de a veinte años, pasidos respectivamente en Sevilla, en Egipto y en Almahdía, parece que debe tomarse como una exaltación del poeta y del sabio en la fantasía popular, y que puede explicarse por la incoherencia del relato de Abensaid, Cormado, como el de Abenjalicán y los de casi todos los biógrafos musulmanes, con retazos de varias narraciones distintas.

Abenjalicán no cita el episodio de la prisión de Abusalt; sólo dice que ael ano 505/1111 fué desterrado de Egipto por Aláfdal Xahanxah; pero continuó en Alejandria durante algún tiempo, dudando [a qué región se dirigiría]; partió el año ŏ06 para Almahdia». Cabe sospechar que Aláfdal le mandara salir de sus territorios, después que lo indultó; pero siempre queda dudoso este punto. También está oscuro si Abusalt volvió a Espana desde Egipto. Benabioseibia dice: «Fué desde España a Egipto y habitó algún tiempo en el Cairo; después volvió a Espaha. Eutró en Egipto alrededor del año

(1) Almacari (loc. cit.) dice que el principe de Almahdía lo envió con una embajada al rey de Egipto y allí fué aprisiopado. 
510/1116.» Que esta entrada en Egipto no fué la primera parece confirmarlo, además de las indicaciones de Abenjalicán, el acto de dedicar Abusalt una poesia a Aláfdal, donde menciona sus campanas contra los francos en Siria, acontecimiento que tuvo lugar durante el reinado de Almustali en los años 493/1099 y 494/1100 (1). $Y$ es de suponer que la poesia fuera escrita a raíz de la campana. ¿Se trata de un segundo viaje desde Almahdia a Egipto? ¿Vino desde Almahdia a Espana, volvien. do a Egipto para terminar en Almahdía? \&Es una errata de Benabioseibia?

Lo que más probable parece, siguiendo el relato de Abenjalicán, es que el 506/1112 llegó Abusalt a Almahdia, ciudad situada al oriente del reino de 'Túnez, donde fué honorablemente recibido por el soberano de la ciudad (2).

Dominaban entonces en Almahdia los zirles, descendientes de Zirf Benatiya (3), virrey de Mauritania en tiempos de Almanzor, a la vez que estaba en todo su apogeo el imperio almorávide, en Africa y Espana, y que eran señores de Bujia los hammadies. Durante el reinado de Temim (1062-1108) y

(1) «Durante el gobierno de Aláfdal, los francos se apoderaron de algunas poblaciones de la costa siria, tomaron Caifa en 493, y Cesarea en 494." (Abenjalicán, I, 160).

(2). Este miemo hocho indica Abonsaid. Abenjalicán dico que lo recibió el soberano Ali Benyahya, que no empezó a reinar hasta el 1116; debe ser errata, porque todos coinciden en decir que dedicó sus obras a Yahya.

(8) Sobre Ziri Benatiya, cfr. Dozy: Histoire des musulmans d'Lspagne, III, 222, y Mercier, E.: Histoire de l'Afri. que Septentrionale (París, Loroux, 1888.91), I, 379. 
de su hijo Yahya (1108-1116) fué bustante próspera la situación de Almahdia, por estar en paz con los normandos de Sicilia; pero Ali (1116-1124) rompió las buenias relaciones con los normandos porque àyudaban a los hammadíes de Bujía, llegando a pedir auxilio al califa almorávide Ali Benyúsuf, lo cual fué causa de que las escuadras de Roger II de Sicilia se presentaran ante Almahdia en 1122, y que al fin lograran apoderarse de la ciudad, en 1146, provocando la caida de Alhasan, hijo de Alí, y con él la dinastía de los ziries (1).

La favorable acogida que los soberanos ziries le dispensaron fué muy agradecida por Abusalt, que compuso alli su libro Risala Almisriya, dedicado al rey Yahya Bentemim Benalmoiz Benbadis. Para Túnez tuvo una gran importancia este viaje de Abusalt, porque él, que tocaba perfectamente el laúd (2) y que había escrito libros sobre música, ensehó allí los cantos populares que se con. servaron largo tiempo en uso (3). En Almahdía tuvo un hijo, llamado Abdeluziz, que llegó a ser un poeta de superior habilidad y un práctico jugador de ajedrez. Murió Abdelaziz en Bujia el ahoo $546 / 1151$ (4).

Honrado por los reyes y los nobles, admirado por el pueblo y engrandecido por la fama (5) de sus poesías y de sus conocimientos científicos, vivió

(1) Cfr. Mercier, ob. cit., II, 57 y sigs.

(2) Benabioseibia, loc, cit.

(3) Abensaid y Almacari, loc, cit.

(4) Abenjalicán, loc, cit.

(5) Abensaíd, lnc. cit. 
Abusalt en Almahdía hasta el dia 2 de Moharram del año 529 (23 Octubre 1134) (1), en que, a causa de una hidropesía (2), rindió su tributo a la muerte, siendo enterrado en el emplazamiento de la actual Monastir. Sobre su tumba mandó poner este epitafio que él mismo había compuesto (3):

- Mientra que me arrastraba

Del mundo la corriente fugitiva,

Yo jamás olvidaba

Que hacia la muerte caminando iba.

Hoy la muerte no temo,

Cuando me siento próximo a morir,

Sino del Juez Supremo

El fallo inevitable que he de oir.

¿Qué destino me espera?

(1) Benabioseibia, loc. cit. Abenjalican (loc. cit.) dice que murió en lunes primer día del año 529 (22 Oatubre 1134). Otros, según el mismo Abenjalicán y Almacari, colocan su muerte el 528, y otros el 546; entre ellos Abensaíd (loc. cit.) - Imad Addin en su libro Jarida (Brockelmann, I, 815), que dice que al fin de una copia do la Hadica de Abusait, que se la había regalado Aláfdal, se hallaba la nota de haber muerto el autor el 12 le Moharram de 546; pero ya Abenjalicán indica que debió ser confusión con la fecha de la muerte de Abdelaziz, hijo de Abusalt, puesto que la de 529 está citada en más autores, y en el Chinán del cadi Arrachid Ben. azzobair, que contiene noticias de poetes de Egipto y vieno a ser un compendio de la Yatima del Tsaalabi (Abenjalicán, I, 146), También da está fecha el Chronicon de Benalatir (ed. Tornberg, XI, 10).

(2) Abenjalicán, loc. cit.

(3) Schack lo tradujo al alemán en su libro, que Valera publicó, vertido al español, bajo el título de Poesía y Arte de los árabes en España y Sicilia, Esta versión do Valera es la que transcribo en el texto. Pons, Historiadores, pági: na 199, la traduce también literalmente. 


\section{$-22-$}

De mis culpas el número es crecido.

¡Cú́n justo el Señor fuera

Castigando a quien tanto le ha ofendido!

Poro ol alma confía

En su misericordia y su perdón

Para gozar dol día

V.en turoso y eterno en su mansión.s

La labor literaria y cientiflca de Abusalt fué enorme, y de ella procuraré dar alguna idea, sin que trate de hacer un catálogo completo de sus obras.

\section{1." Obras poéticas originales.}

Ante todo fué un gran poeta, cuyo nombre coincide con el de otro gran poeta oriental preislámico que se cita en Kitab alagani, III, 179. Benalatir (1) dice: sEn el mismo año (529) murió Abusalt el poetas, y cita dos poesías suyas. Todos sus biógrafos insertan fragmentos más o menos extensos de sus versos (2).

Benabioseibia da en su obra un gran número de extractos de las poesías de Abusalt. Notaré entre las más principales, fuera de su epitafio: dos casidas que a Benabioseibia dió a conocer Abulcásim Alì Bensuleiman, conocido por Benasairafi; una poesia que, según Dáfir Alhadad el Alejundrino, hizo Abusalt cuando se dirigia a Almahdia desde Alejandria; varias laudatorias, en. tre ellas una de alabanza a Abutáhir Yahya Bentemim Benmoiz ben Badis, donde menciona la lle-

(1) Chronicon, loc. cit.

(2) Imad Addin, on Ia Jarida. Cfr. Dozy: Scriptorum arabum loci de Abbadidis (Lugduni Batavorum, 1846), I, 405 . 
gada a Túnez de un rey cristiano con regalos, pidiendo la suspensión de las hostilidades, hecho acaecido el año 505; y otra dedicada a Alátdal, on donde se cita la campafía de éste contra los francos en Siria. Varias descriptivas: de una estrella de la constelación Perseo; de un lugar de Egipto, llamado الحشب الحش de un caballo tordo; de un mosquito; de un astrolabio; de un pebetero; de las Pi. rámides (1). Algunas de carácter religioso: sobre el ascetismo, sobre el tiempo de la adversidad y otra dedicada a su hijo, durante la última enfermedad de Abusalt (2). Y finalmente, buen número de poesías epigramáticas, como la de un médico llamado Xaabán; la misma del mosquito; la de la compra de su casa a un hombre negro; y la hecha a propósito de haber visto que un hermoso adolescente se levantó de su asiento y fué ocupado por un hombre negro. Abenjalicán, que dice que las composiciones poéticas de Abusalt son muchas y buenas, cita algunas, eróticas en su mayoria; $y$ Almacari da otra dedicada a una bella escanciadora (3).

(1) Abensaid, loc. cit.

(2) Almacari y Pona, ob, cit.

(B) Traducida por Pons (ob. cit.). Valera (ob. cit.), I, 143, la traduce así:

Más que el vino que escancia, Vierte rica fragancia

La bella escanciadora, Y más que el vino brilla

En su tersa mejilla

El carmín de la aurora.

Pica, es dulce y agrada

Más que el vino su beso,

$Y$ el vino y su mirada

Hacen perder el seso. 
En la Jarida de Imad Addin se citan también varios fragmentos de versos de Abusalt (1).

Todas estas poesías acaso fueran parte del diván que le atribuye Abenjalicán, cuyo título no cita ninguno de sus biografos.

2. Antologías poéticas.

No sólo era poeta original, sino además hombre muy versado en la historia literaria, como lo prueba el hecho de ser citado como autoridad por los autores orientales. Una de las más nombradas compilaciores de poesias que él compuso fué el Kitab ha.

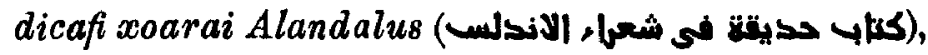
antología compuesta con arreglo al mismo plan que la tan celebrada Yatima (اليتيمة) del Tsaalibi (2).

También se le atribuye un Kitab almilh alasria (كان) acerca de los poetas españoles, que quizá deba identificarse con la anterior.

$3 .^{\circ}$ Obras históricas.

Merece citarse en primer término la Risala $\mathrm{Al}$ misria (رية المسرية). Dedica la obra al rey de Almahdia, Yahya Bentemim, y en ella describe los monumentos que en Egipto habia visto, los médicos, los poetas, los astrónomós y demás personajes notables con quienes se encontró. Una anécdota de este libro nos ha conservado Abulfarach (3), sobre el astrólogo egipcio Rizcalá. Un dia fué a consultarle una mujer; él empezó a hacer su horóscopo

(1) Abenjalicán, loc. cit.

(2) Véase Brockelmann, I, 281; Hachi Jalifa, III, 41, núm. 4461; IV, 146.

(3) Citado por Leclerc: Hist. de la Méd. arabe (París, 1876), II, 74. Ctr. Qifti, ob. cit., pág. 186. 
y a trazar la posición de los astros, a la vez que los describia; miontras tanto la mujer guardó un silencio que el astrólogo juzgó extraño. Por fin la dijo: •Veo desaparecer algo de tu casa; anda con cuidado.»- «Has dicho la verdad*-le contestó la mujer, y le dió una moneda de plata.- ¿ ¿No has tenido una pérdida? - replico el astrólogo.- $₫ \mathrm{Si}$ contestó la mujer-, acabo de perder el dinero que te he dado.s

De la autoridad que esta obra gozó entre los escritores árabes da idea el ser citada por Yacut en su Diccionario geográfico (1) al tratar de las ciudades de Fostat y Barca, del monte llamado de la Luna (جل القمر), y al hablar de los diversos pobladores de Egigto: coptos, cristianos, abes, beréberes, curdos, etc.

4. ${ }^{\circ}$ Obras de medicina.

Un Tratado de los medicamentos simples (4) (الادوية المفربة), ordenado por los miembros del cuerpo semejantes. Este tratado lo cita Abenalbeitar unas veinte veces, aunque estas citas son cortas $y$ de poca importancia (2). Además, un Kitab alinti-

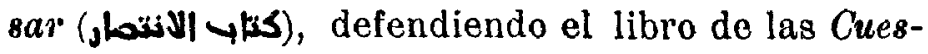
tiones de Honain Benishac de los ataques de Ali Benriduáll.

5. Obras de astronomía.

Un epitome (الوجيز) que compuso por orden del visir Aláfdal. Este lo mostró a su astrónomo Abuabdalá de Alepo, el cual dió su opinión dicien-

(1) Jacut's Gengrafisches Worterbuch (ed. Wüstenfeld, Leipzig, 1869), I, 592; II, 699; IV, 547, 551, 865.

(2) Loclorc, loc. cit. 
do que la obra no podia ser usada por los principiantes en la materia, y a los maestros no les podla ser útil. Además escribió un tratado sobre el

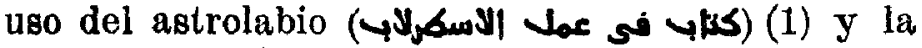
solución de seis problemas astronómicos.

6. Un líbro de música.

7. Un tratado de geometria, y otro tratado sobre los varios sentidos de la voz nocta (punto).

8. Un tratado do logica, titulado Tacuim addihni (تفويه الدمن), que es el objeto principal del pregente trabajo.

De todas estas obras se conservan: El Libro de los medicamentos simples, en la Biblioteca Bodleiana de Oxford (Cfr. Catálogo, I, 578; II, 587); el Tratado sobre el astrolabio, en Berlin, 5798; Leiden, 1073; Bodleiana, I, 967; Ambrosiana, 179; Palatina, 128; Los Seis problemas de Astronomia, Escorial, 646; el libro de Logica, Escorial, 646; una Casida, Berlin, 7682; el tratado sobro los sentidos de la voz nocta (punto), Leyden, 1024 (2).

(1) Abenjalicán dice que estas dos obras astronómicas, la defensa de Honain Benishac, el tratado sobre las medicinas simples y el de lógica, los compuso Abusalt mientras estuvo prisionero en Egipto, y por orden de Aláfadl.

(2) Véase Brockelmann, ob. cit., I, 486. 